\title{
Disorders of Bile Acid Metabolism in Cholesterol Gallstone Disease
}

\author{
Frieder Berr, Ekkehard Pratschke, * Sven Fischer, and Gustav Paumgartner \\ Departments of Medicine II and * Surgery, Klinikum Grosshadern, University of Munich, D-8000 Munich 70, \\ Federal Republic of Germany
}

\begin{abstract}
The aim of the study was to evaluate the metabolism of individual bile acids in patients with cholesterol gallstone disease. Therefore, we determined pool size and turnover of deoxycholic (DCA), cholic (CA), and chenodeoxycholic acid (CDCA) in 23 female gallstone patients classified according to their gallbladder function and in 15 healthy female controls. Gallstone patients had normal hepatic bile acid synthesis, but, depending on gallbladder function, differed with respect to turnover and size of the bile acid pools: Patients with well-emptying gallblad$\operatorname{der}$ (group $A, n=9$ ) had enhanced turnover and reduced pools of CA $(-46 \% ; P<0.01$ vs. controls) and CDCA $(-24 \% ; P$ $<0.05$ ), but normal input and size of the DCA pool. With reduced gallbladder emptying $(<50 \%$ of volume; group $B, n$ $=6$ ), turnover and pools of CA, CDCA, and DCA were similar as in controls. Patients with loss of gallbladder reservoir (group $\mathrm{C}, \boldsymbol{n}=\mathbf{8}) \mathrm{had}$ increased input $(+100 \% ; P<0.01)$ and pool size of DCA $(+45 \% ; P=0.07)$ caused by rapid conversion of $C A$ to DCA, while the pools of CA $(-71 \% ; P<0.001$ vs. controls $)$ and CDCA $(-36 \% ; P<0.05)$ were reduced by enhanced turnover. Thus, in patients with cholesterol gallstones, the pools of primary bile acids are diminished, unless gallbladder emptying is reduced. Furthermore, in a subgroup of gallstone patients, who had completely lost gallbladder function, the CA pool is largely replaced by DCA owing to rapid transfer of CA to the DCA pool. This probably contributes to supersaturation of bile with cholesterol. (J. Clin. Invest. 1992. 90:859-868.) Key words: bile acid metabolism • cholesterol gallstone disease • deoxycholic acid • gallbladder emptying • cholesterol saturation of bile Introduction
\end{abstract}

In most nonobese patients with cholesterol gallstones, the pools of cholic acid (CA) ${ }^{1}$ and chenodeoxycholic (CDCA) are reduced (1-6), and deoxycholic acid (DCA) is often increased in bile (7). Both changes could contribute to supersaturation of bile with cholesterol $(1,7,8)$ : the diminution of the bile acid pools by reducing the mass of bile acids in the enterohepatic

Parts of this work have been published in abstract form (1989. Hepatology. 10:599).

Address reprint requests to Dr. Berr, Department of Medicine II, Klinikum Grosshadern, Marchioninistrasse 15, D-8000 Munich 70, Federal Republic of Germany.

Received for publication 19 February 1991 and in revised form 21 April 1992.

1. Abbreviations used in this paper: $\mathrm{CA}$, cholic acid; $\mathrm{CCK}$, cholecystokinin; CDCA, chenodeoxycholic acid; DCA, deoxycholic acid; FTR, fractional turnover rate.

J. Clin. Invest.

(C) The American Society for Clinical Investigation, Inc.

$0021-9738 / 92 / 09 / 0859 / 10 \quad \$ 2.00$

Volume 90, September 1992, 859-868 circulation (9), the increase of DCA by raising biliary secretion of cholesterol (10).

The small pools of CA and CDCA may be caused by a small gallbladder reservoir (11), by enhanced turnover $(2,5)$, or by inhibition of bile acid synthesis by an oversensitive feedback mechanism (12) or by elevated levels of DCA $(13,14)$. An increased fraction of DCA in bile could be caused by high input and large pool size of DCA. CA is nearly completely $7 \alpha$-dehydroxylated to DCA by anaerobic bacteria in the colon $(7,15$, 16 ), but only $30-40 \%$ of this DCA is absorbed from the intestine (17). The DCA pool could be expanded by increased input of DCA owing to increased synthesis of the precursor CA or to an increased fraction of CA transferred to the DCA pool.

It is still unclear which of the above factors account(s) for the reduction in CA and CDCA pool size and which for an increase in biliary DCA. Therefore, we studied the size and the turnover of the pools of CA, CDCA, and DCA in gallstone patients classified according to reservoir volume and emptying of the gallbladder.

\section{Methods}

Study subjects (Table I). The study comprised 15 female controls with normal gallbladder function and 23 female patients with radiolucent gallbladder stones. All were Caucasians. The mean age and the mean body mass index of the control subjects were $34 \mathrm{yr}$ and $23.09 \mathrm{~kg} / \mathrm{m}^{2}$, respectively, and of the gallstone patients $44 \mathrm{yr}$ and $24.35 \mathrm{~kg} / \mathrm{m}^{2}$. None was grossly obese $\left(>30 \mathrm{~kg} / \mathrm{m}^{2}\right)$ or had evidence of hepatic, intestinal, or renal disease, cholangitis, diabetes mellitus, or thyroid dysfunction. None had taken antibiotics, lipid-lowering drugs, or hormones within the last four weeks. Control subjects were 13 healthy, paid volunteers recruited among employees at the University Hospital (Munich) and two otherwise healthy patients, one with a gallbladder polyp and the other with polycystic liver disease.

All participants were classified according to the reservoir function and the emptying of the gallbladder. Gallstone patients with reservoir function $(n=15)$ showed on ultrasound normal wall echoes of the gallbladder, which was filled to $<30 \%(\mathrm{vol} / \mathrm{vol})$ with stones; 13 of them had an opacified gallbladder on oral cholecystography, 2 had no cholecystography, but contracted the gallbladder in response to cholecystokinin (CCK). Emptying of the gallbladder was classified as normal, when on ultrasound $(18) \geq 50 \%$ of the volume had emptied in response $\operatorname{CCK}(19,20)$. Nine of these gallstone patients had normal emptying of the gallbladder (group A, $n=9$ ) and six had reduced emptying (group B, $n=6$ ). The gallstone patients without reservoir function of the gallbladder (group $\mathrm{C}, n=8$ ) showed no opacification on oral cholecystography. Occlusion of the cystic duct $(n=5)$ or a shrunken gallbladder $(n=3)$ were confirmed by endoscopic retrograde cholangiography and/or subsequent cholecystectomy. Controls showed on ultrasound a sludge-free lumen, normal wall echoes, and normal emptying of the gallbladder in response to CCK.

Study protocol. The protocol had been approved by the Ethics Committee of the Hospitals of the University of Munich. All participants gave their written informed consent. The protocol (21) consisted of $(a)$ stable isotope kinetics of CA, CDCA, and DCA (22), $(b)$ serial sonographic estimation of gallbladder volume (18) during an intrave- 
Table I. Characteristics of Gallstone Patients and Control Subjects

\begin{tabular}{|c|c|c|c|c|c|c|c|c|c|}
\hline \multirow{2}{*}{$\begin{array}{c}\text { Subject } \\
\text { No. }\end{array}$} & \multirow[b]{2}{*}{ Diagnosis } & \multirow[b]{2}{*}{ Treatment* } & \multirow[b]{2}{*}{ Age } & \multirow{2}{*}{$\begin{array}{c}\text { Body } \\
\text { weight }\end{array}$} & \multirow{2}{*}{$\begin{array}{c}\text { Body } \\
\text { mass } \\
\text { index }\end{array}$} & \multirow{2}{*}{$\begin{array}{l}\text { Dietary } \\
\text { cholesterol } \\
\text { intake }\end{array}$} & \multicolumn{2}{|c|}{ Serum lipids } & \multirow{2}{*}{$\begin{array}{c}\text { Stool } \\
\text { frequency }\end{array}$} \\
\hline & & & & & & & Triglycerides & Cholesterol & \\
\hline & & & $(y r)$ & $(\mathrm{kg})$ & $\left(\mathrm{kg} / \mathrm{m}^{2}\right)$ & $(m g / d)$ & $(m g / d l)$ & $(m g / d l)$ & $\left(d^{-1}\right)$ \\
\hline
\end{tabular}

Gallstone patients

\begin{tabular}{|c|c|c|c|c|c|c|c|c|c|}
\hline 1 & GBS & $\mathrm{CCX}$ & 39 & 71 & 27.73 & 627 & 151 & 227 & 0.6 \\
\hline 2 & GBS & $\mathrm{CCX}$ & 44 & 67 & 24.61 & 267 & 56 & 160 & 1.0 \\
\hline 3 & GBS $^{\ddagger}$ & CCX & 38 & 55 & 23.81 & 349 & 130 & 189 & 1.0 \\
\hline 4 & GBS & $\mathrm{CCX}$ & 35 & 76 & 26.30 & 207 & 90 & 156 & 1.0 \\
\hline 5 & GBS & ESWL & 35 & 66 & 25.78 & 624 & 44 & 151 & 0.4 \\
\hline 6 & GBS & ESWL & 42 & 60 & 21.26 & 286 & 109 & 189 & 1.0 \\
\hline 7 & GBS & none & 27 & 54 & 20.83 & 320 & 87 & 164 & 0.7 \\
\hline 8 & GBS & $\mathrm{CCX}$ & 34 & 53 & 23.56 & 524 & 154 & 192 & 1.0 \\
\hline 9 & GBS & ESWL & 41 & 67 & 24.61 & 328 & 118 & 209 & 1.0 \\
\hline $\bar{X}$ & $(n=9)$ & & 37.2 & 63.2 & 24.28 & 392 & 104 & 182 & 0.86 \\
\hline SD & & & 5.1 & 8.1 & 2.24 & 158 & 39 & 26 & 0.23 \\
\hline
\end{tabular}

Group B: with preserved reservoir and reduced emptying of the gallbladder

$\begin{aligned} 10 & \text { GBS } \\ 11 & \text { GBS } \\ 12 & \text { GBS } \\ 13 & \text { GBS } \\ 14 & \text { GBS } \\ 15 & \text { GBS } \\ \bar{X} & (n=6) \\ \text { SD } & \end{aligned}$

$\begin{array}{lrrrrrrr}\text { CCX } & 37 & 58 & 23.53 & 450 & 83 & 194 & 1.0 \\ \text { CCX } & 38 & 70 & 25.71 & 450 & 184 & 233 & 0.6 \\ \text { CCX } & 44 & 71 & 23.72 & 573 & 129 & 239 & 1.0 \\ \text { ESWL } & 49 & 54 & 21.09 & 360 & 184 & 208 & 1.2 \\ \text { CCX } & 44 & 59 & 23.05 & 464 & 85 & 218 & 0.5 \\ \text { ESWL } & 38 & 71 & 25.16 & 375 & 54 & 187 & 1.0 \\ & 41.7 & 63.8 & 23.71 & 436 & 114 & 213 & 0.88 \\ & 4.8 & 7.7 & 1.64 & 64 & 48 & 21 & 0.27\end{array}$

$\begin{aligned} 16 & \text { OCD, GBS } \\ 17 & \text { SGB, GBS } \\ 18 & \text { SGB, GBS } \\ 19 & \text { OCD, GBS } \\ 20 & \text { OCD, GBS } \\ 21 & \text { OCD, GBS } \\ 22 & \text { SGB, GBS } \\ 23 & \text { SGB, OCD, GBS } \\ \bar{X} & (n=8) \\ \text { SD } & \end{aligned}$

Group C: without reservoir function of the gallbladder

$\begin{array}{lllrrrrr}\text { CCX } & 40 & 66 & 23.95 & 363 & 174 & 114 & 1.00 \\ \text { CCX } & 45 & 53 & 21.50 & 404 & 69 & 232 & 1.00 \\ \text { CCX } & 48 & 78 & 26.99 & 440 & 107 & 245 & 0.60 \\ \text { none } & 80 & 63 & 23.71 & 400 & 78 & 206 & 0.70 \\ \text { CCX } & 68 & 63 & 24.11 & 340 & 320 & 197 & 0.80 \\ \text { CCX } & 30 & 90 & 29.79 & - & 183 & 241 & 0.80 \\ \text { CCX } & 45 & 73 & 25.86 & 570 & 215 & 229 & 1.00 \\ \text { CCX } & 69 & 62 & 23.34 & 415 & 108 & 246 & 2.00 \\ & 53.1 & 68.5 & 24.91 & 419 & 157 & 214 & 0.99 \\ & 17.2 & 11.5 & 2.57 & 74 & 84 & 44 & 0.44\end{array}$

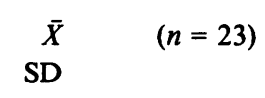

Groups A, B, and C

Control subjects

\begin{tabular}{|c|c|c|c|c|c|c|c|c|c|}
\hline 1 & GBpolyp & $\mathrm{CCX}$ & 44 & 52 & 21.10 & 196 & 71 & 218 & 1.0 \\
\hline 2 & Healthy & none & 47 & 69 & 24.74 & 566 & 62 & 165 & 0.8 \\
\hline 3 & Healthy & none & 33 & 55 & 20.96 & 585 & 162 & 195 & 0.8 \\
\hline 4 & Healthy & none & 26 & 72 & 25.21 & 234 & 74 & 176 & 1.0 \\
\hline 5 & Healthy & none & 23 & 62 & 20.24 & 259 & 68 & 186 & 1.2 \\
\hline 6 & Healthy & none & 26 & 64 & 24.69 & 543 & 52 & 214 & 0.6 \\
\hline 7 & Healthy & none & 47 & 64 & 25.64 & 325 & 90 & 231 & 1.0 \\
\hline 8 & Healthy & none & 23 & 52 & 18.21 & 272 & 67 & 183 & 1.0 \\
\hline 9 & Healthy & none & 22 & 59 & 22.21 & 602 & 92 & 179 & 1.2 \\
\hline 10 & Healthy & none & 45 & 71 & 26.40 & 334 & 88 & 213 & 0.8 \\
\hline
\end{tabular}


Table I. (Continued)

\begin{tabular}{|c|c|c|c|c|c|c|c|c|c|}
\hline \multirow[b]{2}{*}{$\begin{array}{c}\text { Subject } \\
\text { No. }\end{array}$} & \multirow[b]{2}{*}{ Diagnosis } & \multirow[b]{2}{*}{ Treatment* } & \multirow[b]{2}{*}{ Age } & \multirow[b]{2}{*}{$\begin{array}{c}\text { Body } \\
\text { weight }\end{array}$} & \multirow{2}{*}{$\begin{array}{l}\text { Body } \\
\text { mass } \\
\text { index }\end{array}$} & \multirow{2}{*}{$\begin{array}{l}\text { Dietary } \\
\text { cholesterol } \\
\text { intake }\end{array}$} & \multicolumn{2}{|c|}{ Serum lipids } & \multirow[b]{2}{*}{$\begin{array}{c}\text { Stool } \\
\text { frequenc }\end{array}$} \\
\hline & & & & & & & Triglycerides & Cholesterol & \\
\hline & & & $(y r)$ & $(\mathrm{kg})$ & $\left(\mathrm{kg} / \mathrm{m}^{2}\right)$ & $(m g / d)$ & $(m g / d l)$ & $(m g / d l)$ & $\left(d^{-1}\right)$ \\
\hline \multicolumn{10}{|c|}{ Control subjects (continued) } \\
\hline 11 & Healthy & none & 36 & 58 & 20.80 & 218 & 96 & 238 & 1.0 \\
\hline 12 & Healthy & none & 23 & 67 & 24.61 & 239 & 155 & 195 & 0.6 \\
\hline 13 & PLD & $\mathrm{CCX}$ & 48 & 66 & 24.84 & 253 & 110 & 232 & 0.8 \\
\hline 14 & Healthy & none & 36 & 50 & 19.53 & 435 & 82 & 204 & 1.0 \\
\hline 15 & Healthy & none & 33 & 72 & 27.13 & 188 & 115 & 245 & 1.2 \\
\hline $\bar{X}$ & $(n=15)$ & & 34.1 & 62.2 & 23.09 & 350 & 92 & 205 & 0.93 \\
\hline SD & & & 10.0 & 7.5 & 2.78 & 153 & 32 & 25 & 0.20 \\
\hline
\end{tabular}

Abbreviations: CCX, cholecystectomy; ESWL, extracorporeal shock wave lithotripsy; GB, gallbladder; GBS, gallbladder stones; OCD, occluded cystic duct; PLD, polycystic liver disease; SGB, shrunken GB.

* All studies were concluded before treatment.

${ }^{\ddagger}$ Subject had an aortic bioprosthesis for $1 \mathrm{yr}$.

nous infusion of CCK $(19,20)$ with $(c)$ sampling of unstimulated and CCK-stimulated duodenal bile and $(d)$ records of dietary intake and bowel habits kept for $7 \mathrm{~d}$ to estimate daily intake of cholesterol (23) and average stool frequency.

Bile acid kinetics. Pool sizes and turnover rates of CA, CDCA, and DCA were simultaneously determined from postprandial serum samples obtained before and for $4 \mathrm{~d}$ after oral intake of a single dose of marker bile acids ( $50 \mathrm{mg}$ each) which were labeled with stable isotopes $\left({ }^{13} \mathrm{C}\right.$ or $\left.{ }^{2} \mathrm{H}\right)(22)$. In the first three participants (subjects 1 and 2 in group A and subject 1 in controls), only kinetics of CDCA and DCA were determined using ${ }^{13} \mathrm{C}$-labeled marker bile acids; their $\mathrm{CA}$ pool size was calculated as the product of the CDCA pool size times the CA/ CDCA molar ratio of intraoperative gallbladder bile (24). Marker bile acids $\left(24-{ }^{13} \mathrm{C}-\mathrm{CA}, 90 \%{ }^{13} \mathrm{C} ; 24-{ }^{13} \mathrm{C}-\mathrm{CDCA}, 91.9 \%{ }^{13} \mathrm{C} ; 24-{ }^{13} \mathrm{C}\right.$-DCA, 91.5\% ${ }^{13} \mathrm{C} ; 2,2,4,4-{ }^{2} \mathrm{H}_{4}$-DCA, $99.4 \%{ }^{2} \mathrm{H}_{4}$ ) were purchased from Merck Sharp \& Dohme, Montreal, Canada. Materials, sample preparation, and measurement of isotope ratios of individual bile acids using combined capillary gas-liquid chromatography-mass spectrometry-selected ion monitoring have previously been described (22). From the isotopic enrichment $R$ and the natural abundance $R_{0}$ (before intake of label) of ${ }^{13} \mathrm{C}$ or ${ }^{2} \mathrm{H}_{4}$ of the respective bile acid, atom percent excess (APE) was calculated (22):

$A P E=R-R_{0} / 1+\left(R-R_{0}\right) \times 100(\%)$

The APE vs. time curve showed monoexponential first-order decay with excellent fit $(r>0.90)$. Pool size and synthesis rate were calculated:

Pool size $=$ dose $\times b \times 100 / e^{a}-$ dose

Synthesis rate $=$ pool size $\times F T R$

where $a$ is the $y$-intercept and fractional turnover rate (FTR) the slope of the first-order decay curve of APE, and $b$ the degree of labeling of the marker bile acid. Hepatic synthesis rate of bile acids was calculated as the sum of CA and CDCA synthesis rates and total bile acid pool size as the sum of the pools of CA, CDCA, and DCA. The transfer of ${ }^{13} \mathrm{C}$ label from CA to the DCA pool was estimated from the amount of excess $\left[{ }^{13} \mathrm{C}\right] \mathrm{DCA}(21)$ :

Excess $\left[{ }^{13} \mathrm{C}\right] \mathrm{DCA}_{t}=A P E_{\left[{ }^{13} \mathrm{C}\right] \mathrm{DCA}, t} \times$ pool size $\mathrm{DCA}_{\mathrm{DA}}$

$\times$ body weight $/ 100$ where $A P E_{\mathrm{t}}$ is the APE in the sample drawn at time $t$ after intake of 50 $\mathrm{mg}$ of $\left[{ }^{13} \mathrm{C}\right] \mathrm{CA}$. The pool size of DCA was estimated from the dose and the decay of $\left[{ }^{2} \mathrm{H}_{4}\right]$ DCA.

Gallbladder reservoir and emptying (Table II). The fasting volume was calculated according to the sum of cylinders method (18) from sonographic images of the gallbladder in the maximum longitudinal and anterior-posterior diameters. The recordings (Sonolayer B, Toshiba Corp., Tokyo) were taken in triplicate on the morning after a 12-h fast. The average coefficient of variation for triplicate determination $(n=30)$ was $6.0 \% \pm 3.9 \%(\overline{\mathrm{X}} \pm \mathrm{SD})$. Serial volumes (every $5 \mathrm{~min}$ ) and the first-order rate constant of emptying were determined (18) during a subsequent intravenous infusion of CCK $\left(0.02 \mathrm{U} \mathrm{kg}^{-1} \mathrm{~min}^{-1}\right.$; Kabi-Vitrum, Stockholm) (20).

The fasting volume of the gallbladder was $24.3 \pm 8.8 \mathrm{ml}$ in gallstone patients with gallbladder reservoir (groups A and B) and $21.6 \pm 8.8 \mathrm{ml}$ in controls (NS). The residual volume $(10.6 \pm 7.9$ vs. $2.3 \pm 1.6 \mathrm{ml} ; P$ $<0.01$ ), even when corrected for stone volume (Table II; $P<0.05$ ), was larger in gallstone patients than in controls and the fraction of volume emptied $\left(F_{\mathrm{e}}\right)$ was diminished $(66 \pm 27 \%$ vs. $89 \pm 6 \% ; P<0.02)$. The gallstone patients with reduced emptying of the gallbladder (group B) differed from gallstone patients with normal emptying (group A) with regard to the fraction of gallbladder volume emptied ( $38 \pm 10 \%$ vs. $86 \pm 12 \%)$, residual volume $(14.5 \pm 6.7$ vs. $2.7 \pm 2.8 \mathrm{ml}$, corrected for stone volume; $P<0.01)$, and rate of emptying $(0.020 \pm 0.007$ vs. $0.069 \pm 0.035 \mathrm{~min}^{-1} ; P<0.01$ ) (Fig. 1).

Analysis of bile and gallstones. Duodenal bile was sampled through a thin Teflon duodenal tube between 8 and 10 a.m. after an overnight $(12 \mathrm{~h})$ fast. Bile was collected during the CCK infusion from 10 to 20 min and from 20 to $30 \mathrm{~min}$, light-shielded on ice, and the darkest fraction sampled $(3 \mathrm{ml})$. The samples were kept in chloroform $/$ methanol ( $1: 2 \mathrm{vol} / \mathrm{vol} ; 0.5 \mathrm{ml}$ of bile per $7.5 \mathrm{ml}$ of solvent) at $-20^{\circ} \mathrm{C}$ and analyzed for cholesterol (25) and lipid-soluble phosphorus (26) by colorimetric tests and for bile acids by gas-liquid chromatography (27). Cholesterol saturation was calculated (28) assuming a total lipid concentration of $10 \mathrm{~g} / \mathrm{dl}$ in undiluted bile (29). Gallstones obtained at cholecystectomy were assessed for volume (by water displacement) and cholesterol content (21). In seven patients gallstone volume (V) was calculated from sonographic estimates of the maximum diameter $\left(d_{1}=2 a\right)$ and the maximal perpendicular diameter $\left(d_{2}=2 b\right)$ assuming a three-dimensional ellipsoid $\left(V=4 / 3 a b^{2}\right)$ (Table II).

Statistical analysis. Data are given as $\overline{\mathrm{X}} \pm \mathrm{SD}$. The statistical significance of differences between controls and patient groups $\mathrm{A}-\mathrm{C}$ was tested by one way ANOVA using the program Solo 101 of BMDP 
Table II. Gallbladder Motility and Gallstone Characteristics

\begin{tabular}{|c|c|c|c|c|c|c|c|c|c|}
\hline & \multirow[b]{2}{*}{$\begin{array}{l}\text { Fasting } \\
\text { volume }\end{array}$} & \multirow{2}{*}{$\begin{array}{l}\text { Fasting } \\
\text { volume } \\
\text { (corr.)* }\end{array}$} & \multirow{2}{*}{$\begin{array}{l}\text { Residual } \\
\text { volume } \\
\text { (corr.) }\end{array}$} & \multirow[b]{2}{*}{$F_{\mathrm{e}}$} & \multirow[b]{2}{*}{$k_{\mathrm{e}}$} & \multirow[b]{2}{*}{$t_{1 / 2}$} & \multicolumn{3}{|c|}{ Gallstones } \\
\hline & & & & & & & $n$ & Volume & Cholestero \\
\hline : & & $(m l)$ & & (\%) & $\left(\mathrm{min}^{-1}\right)$ & (min) & & $(m l)$ & $(\% d r y w t)$ \\
\hline \multicolumn{10}{|c|}{ Gallstone patients } \\
\hline \multicolumn{10}{|c|}{ Group A: with reservoir and emptying of the gallbladder } \\
\hline 1 & 19.0 & 16.0 & 8.0 & 50.0 & 0.058 & 12.0 & 2 & 3.0 & 79 \\
\hline 2 & 32.0 & 24.5 & 8.5 & 65.3 & 0.059 & 11.8 & 2 & 7.5 & 65 \\
\hline 3 & 18.8 & 18.3 & 1.0 & 94.5 & 0.100 & 6.9 & 4 & 0.5 & 73 \\
\hline 4 & 15.5 & 14.4 & 0.4 & 97.2 & 0.090 & 7.7 & 40 & 1.1 & 70 \\
\hline 5 & 20.5 & 17.4 & 1.6 & 90.8 & 0.050 & 13.9 & 1 & 3.1 & ND \\
\hline 6 & 36.5 & 34.3 & 1.0 & 97.1 & 0.140 & 5.0 & 2 & 2.2 & ND \\
\hline 7 & 10.3 & 8.6 & 1.3 & 84.9 & 0.045 & 15.4 & 3 & 1.7 & ND \\
\hline 8 & 23.1 & 20.3 & 0.6 & 97.0 & 0.039 & 17.8 & 4 & 2.8 & 78 \\
\hline 9 & 34.8 & 25.8 & 5.3 & 79.5 & 0.037 & 18.7 & 1 & 9.0 & ND \\
\hline $\bar{X}(n=9)$ & 23.4 & 20.0 & 2.7 & 86.1 & 0.069 & 12.1 & 7 & 3.4 & 73 \\
\hline SD & 9.1 & 7.5 & 2.8 & 12.4 & 0.035 & 4.8 & 13 & 2.9 & 6 \\
\hline
\end{tabular}

Group B: with preserved reservoir and reduced emptying of the gallbladder

\begin{tabular}{|c|c|c|c|c|c|c|c|c|c|}
\hline 10 & 19.5 & 17.3 & 11.3 & 34.7 & 0.023 & 30.1 & 76 & 2.2 & 75 \\
\hline 11 & 20.0 & 16.5 & 9.5 & 42.4 & 0.013 & 53.3 & 8 & 3.5 & 83 \\
\hline 12 & 39.5 & 38.0 & 22.0 & 42.1 & 0.024 & 28.9 & 2 & 1.5 & 78 \\
\hline 13 & 15.4 & 14.0 & 8.2 & 41.4 & 0.012 & 57.8 & 1 & 1.4 & ND \\
\hline 14 & 28.2 & 22.2 & 12.0 & 45.9 & 0.029 & 23.9 & 2 & 6.0 & 73 \\
\hline 15 & 31.5 & 29.7 & 24.0 & 19.2 & 0.020 & 34.7 & 1 & 1.8 & ND \\
\hline$X(n=6)$ & 25.7 & 23.0 & 14.5 & 37.6 & 0.020 & 38.1 & 15 & 2.7 & 77 \\
\hline SD & 9.0 & 9.2 & 6.7 & 9.7 & 0.007 & 14.0 & 30 & 1.8 & 4 \\
\hline \multicolumn{10}{|c|}{ Groups $\mathrm{A}$ and $\mathrm{B}(n=15)$} \\
\hline $\bar{X}$ & 24.3 & 21.2 & 7.7 & 65.5 & 0.049 & 22.5 & 10 & 3.2 & 75 \\
\hline SD & 8.8 & 8.0 & 7.5 & 27.3 & 0.036 & 16.0 & 21 & 2.5 & \\
\hline
\end{tabular}

Group C: without reservoir function of the gallbladder

\begin{tabular}{|c|c|c|c|c|c|c|c|c|}
\hline 16 & & $0^{5}$ & $0^{5}$ & & & 8 & 8.5 & 78 \\
\hline 17 & 12.5 & 3.5 & 3.5 & 0 & 0 & 9 & 9.2 & 83 \\
\hline 18 & 2.0 & 1.0 & 1.0 & 0 . & 0 & 11 & 1.0 & 77 \\
\hline 19 & & 0 & 0 & & & ND & $11.0^{\ddagger}$ & ND \\
\hline 20 & & 0 & 0 & & & 3 & 7.5 & ND \\
\hline 21 & & 0 & 0 & & & 32 & 8.6 & 67 \\
\hline 22 & 12.5 & 2.0 & 2.0 & 0 & 0 & 9 & 10.5 & 71 \\
\hline 23 & & 0 & 0 & & & 1 & 8.0 & 80 \\
\hline $\bar{X}$ & 9.0 & 0.8 & 0.8 & 0 & 0 & 10 & 8.0 & 76 \\
\hline SD & 5.7 & 1.3 & 1.3 & & & 10 & 3.1 & 6 \\
\hline
\end{tabular}

Controls with gallbladder reservoir and emptying

$\begin{array}{rrrrrrr}1 & 13.0 & 1.5 & 88.5 & 0.100 & 6.9 & 0 \\ 2 & 18.5 & 1.5 & 91.5 & 0.059 & 11.7 & 0 \\ 3 & 45.5 & 2.0 & 95.6 & 0.067 & 10.3 & 0 \\ 4 & 12.5 & 1.5 & 88.0 & 0.086 & 8.1 & 0 \\ 5 & 17.0 & 1.2 & 92.9 & 0.081 & 8.6 & 0 \\ 6 & 22.0 & 4.4 & 80.0 & 0.033 & 21.0 & 0 \\ 7 & 17.7 & 2.2 & 87.4 & 0.062 & 11.2 & 0 \\ 8 & 29.9 & 7.4 & 75.3 & 0.034 & 20.4 & 0 \\ 9 & 24.0 & 2.0 & 91.7 & 0.056 & 12.4 & 0\end{array}$




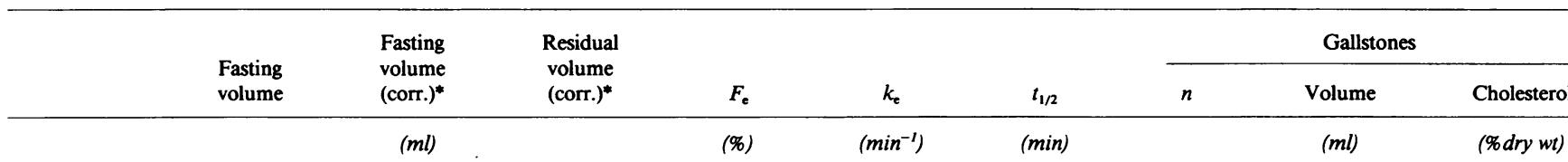

Controls with gallbladder reservoir and emptying (continued)

$\begin{array}{crrrrrrr}10 & 28.0 & 2.5 & 91.7 & 0.059 & 11.7 & 0 & 0 \\ 11 & 24.0 & 1.2 & 95.0 & 0.106 & 6.5 & 0 & 0 \\ 12 & 14.5 & 2.2 & 84.8 & 0.080 & 8.7 & 0 & \\ 13 & 15.0 & 1.5 & 90.0 & 0.084 & 8.3 & 0 & \\ 14 & 28.5 & 1.4 & 95.1 & 0.082 & 8.5 & 0 & \\ 15 & 14.2 & 1.4 & 90.1 & 0.060 & 11.6 & & \\ \bar{X}(n=15) & 21.6 & 2.3 & 89.2 & 0.070 & 11.1 & 0 & \\ \text { SD } & 8.8 & 1.6 & 5.6 & 0.021 & 4.3 & 0\end{array}$

$F_{\mathrm{e}}$, fraction (\%) of gallbladder fasting volume emptied (18); $k_{\mathrm{e}}$, fractional rate constant of emptying (18) during CCK infusion (20); ND, not determined.

* Corrected by subtraction of total volume of stones.

${ }^{\ddagger}$ Several stones with estimated total volume of $11 \mathrm{ml}$.

$\S$ Occluded cystic duct of the gallbladder. Therefore the corrected fasting and residual volumes were arbitrarily set to zero.

Statistics Corp., Sepulveda, CA. Differences were confirmed by unpaired $t$ test (for equal variance) or by Satterthwaite's $t$ test (for unequal variance) at the level of $P<0.05(30)$. Associations between variables were searched with scatter plots and confirmed by linear regression analysis $(31)$.

\section{Results}

Bile acid pools (Table III). The total group of gallstone patients had a slightly smaller $(-26 \% ; P<0.01)$ total bile acid pool $\left(52.4 \pm 14.9 \mathrm{~mol} \mathrm{~kg}^{-1} ; n=23\right)$ than controls $(70.7 \pm 20.5$ mol kg $\left.{ }^{-1} ; n=15\right)$, reduced pools of CA $(-42 \%, P<0.01)$ and CDCA $(-29 \%, P<0.02)$ and a normal pool of DCA $(+8 \%)$. The pools of CA, CDCA, and DCA turned over at higher fractional rates $(+46 \%, P=0.07 ;+46 \%,+39 \%, P<0.02)$. Sub-

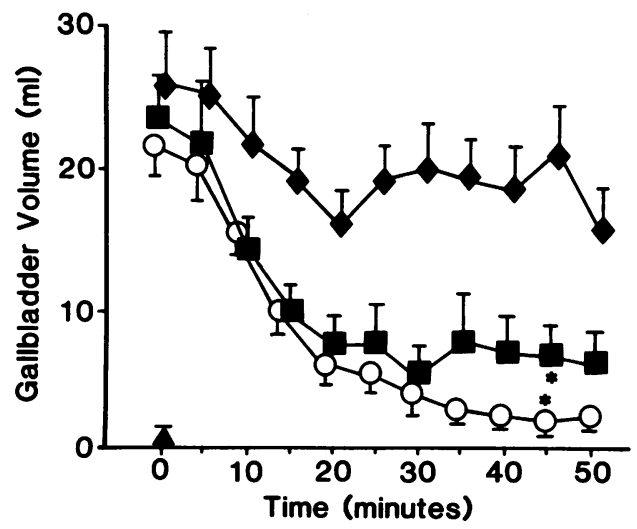

Figure 1. Time course of emptying of the gallbladder during intravenous infusion of CCK ( 0.02 Ivy dog units $\left.\mathrm{kg}^{-1} \mathrm{~min}^{-1}\right) . \overline{\mathrm{X}} \pm \mathrm{SEM}$; gallbladder volume not corrected for stone volume. (o) Controls $(n$ $=15) ;(\square)$ gallstone patients with well-emptying gallbladder (group A; $n=9) ;(\bullet)$ gallstone patients with reduced emptying $(<50)$ of the gallbladder (group B; $n=6$ ); ( $)$ gallstone patients without gallbladder reservoir (group $C ; n=8$ ). *Significantly different $(P<0.05$ ). groups $(\mathrm{A}-\mathrm{C})$ of gallstone patients classified according to gallbladder function showed three different bile acid pool patterns (Fig. 2): (a) Patients with normal emptying (group A) had reduced pools of total bile acids $(-33 \%, P<0.05), \mathrm{CA}(-46 \%$, $P<0.01)$, and CDCA $(-24 \%, P<0.05$ vs. controls) with enhanced fractional turnover $(\mathrm{CA}+54 \%, P<0.05$; CDCA $+38 \%$, NS) and normal size and FTR of the DCA pool. (b) Patients with defective emptying of the gallbladder (group B) had normal-sized pools of total bile acids, CA, and DCA. The CDCA pool was reduced by $23 \%$, but this was not statistically significant. The fractional turnover rates of CA, CDCA, and DCA were normal. $(c)$ The patients without gallbladder reservoir (group C), however, had an expanded DCA pool $(+45 \%$, $P=0.07)$ combined with reduced pools of CA $(-71 \%, P$ $<0.001)$ and CDCA $(-37 \%, P<0.05)$. Their fractional turnover rates of $\mathrm{CA}(+97 \%, P<0.05)$ and CDCA $(+83 \%, P$ $<0.01$ vs. control) were enhanced (Table III).

Hepatic synthesis of bile acids was determined in 16 gallstone patients and 13 controls. Gallstone patients and controls had a normal rate of hepatic synthesis of bile acids (15.6 \pm 4.6 vs. $16.1 \pm 8.5 \mathrm{~mol} \mathrm{~kg}^{-1} \mathrm{~d}^{-1}$ ), both of CA and CDCA (Table III, groups A-C vs. controls). In one control (subject 10) and five gallstone patients (subject 9 in group A and subjects 16, 18, 20, and 22 in group $\mathrm{C}$ ), CA synthesis was not measurable, in that the $\left[{ }^{13} \mathrm{C}\right] \mathrm{CA}$ marker was converted to $\left[{ }^{13} \mathrm{C}\right] \mathrm{DCA}$ within $24 \mathrm{~h}$ (see below). The input rate of DCA in these subjects $(9.4 \pm 3.2$ mol kg-1 $\mathrm{d}^{-1}$ ) was comparable to the synthesis rate of the precursor CA in controls $\left(10.2 \pm 5.6 \mathrm{~mol} \mathrm{~kg}^{-1} \mathrm{~d}^{-1}\right)$; the sum of their CDCA synthesis and DCA input rates $(19.3 \pm 3.7 \mathrm{~mol}$ $\left.\mathrm{kg}^{-1} \mathrm{~d}^{-1} ; n=5\right)$ matched $(+20 \%, \mathrm{NS})$ hepatic synthesis rate of bile acids in controls.

Input of DCA was $38 \%$ higher in the total group of gallstone patients $\left(5.8 \pm 3.1 \mu \mathrm{mol} \mathrm{kg} \mathrm{kg}^{-1} \mathrm{~d}^{-1}\right)$ than in controls $(4.2 \pm 3.0$ $\mu \mathrm{mol} \mathrm{kg} \mathrm{kg}^{-1} \mathrm{~d}^{-1}$, but this difference did not reach statistical significance. Only subgroup $C$ showed a significant twofold increase of DCA input $(P<0.01$ vs. controls and group A\&B). Except for one woman (subject 17), all in group $C$ had the same disorder of bile acid kinetics characterized by enhanced 
Table III. Kinetics of Bile Acids in Control Subjects and Gallstone Patients

\begin{tabular}{|c|c|c|c|c|c|c|c|c|c|c|}
\hline \multirow{2}{*}{$\begin{array}{c}\text { Subject } \\
\text { No. }\end{array}$} & \multicolumn{3}{|c|}{ CDCA } & \multicolumn{3}{|c|}{$\mathrm{CA}$} & \multicolumn{3}{|c|}{ DCA } & \multirow{2}{*}{$\begin{array}{l}\text { Transfer of } \\
\text { Ca to } \mathrm{DCA}^{*}\end{array}$} \\
\hline & Pool & Synthesis & FTR & Pool & Synthesis & FTR & Pool & Input & FTR & \\
\hline
\end{tabular}

Gallstone patients

Group A: with reservoir and emptying of the gallbladder

\begin{tabular}{|c|c|c|c|c|c|c|c|c|c|c|}
\hline 1 & 19.4 & 5.2 & 0.27 & $17.7^{\ddagger}$ & ND & ND & 13.3 & 2.6 & 0.20 & ND \\
\hline 2 & 14.8 & 2.5 & 0.17 & $20.7^{\ddagger}$ & ND & ND & 9.2 & 1.8 & 0.28 & ND \\
\hline 3 & 14.5 & 7.5 & 0.52 & 12.9 & 14.3 & 1.18 & 14.4 & 5.7 & 0.40 & 40 \\
\hline 4 & 13.6 & 5.4 & 0.40 & 17.9 & 8.1 & 0.45 & 16.2 & 5.9 & 0.37 & 73 \\
\hline 5 & 12.9 & 4.8 & 0.37 & 14.4 & 5.2 & 0.36 & 11.4 & 3.9 & 0.34 & 75 \\
\hline 6 & 42.4 & 11.4 & 0.27 & 17.1 & 10.6 & 0.62 & 3.9 & 1.9 & 0.49 & 18 \\
\hline 7 & 16.9 & 5.1 & 0.30 & 22.0 & 10.8 & 0.49 & 7.7 & 5.0 & 0.64 & 46 \\
\hline 8 & 25.7 & 5.4 & 0.21 & 14.7 & 5.0 & 0.34 & 2.5 & 1.0 & 0.39 & 19 \\
\hline 9 & 23.0 & 11.3 & 0.49 & 0 & & & 24.1 & 7.9 & 0.33 & \\
\hline $\bar{X}(n=9)$ & 20.4 & 6.5 & 0.33 & 15.3 & 9.0 & 0.57 & 11.4 & 4.0 & 0.38 & 45.2 \\
\hline SD & 9.4 & 3.0 & 0.12 & 6.4 & 3.6 & 0.31 & 6.6 & 2.3 & 0.13 & 25.0 \\
\hline
\end{tabular}

Group B: with preserved reservoir and reduced emptying of the gallbladder

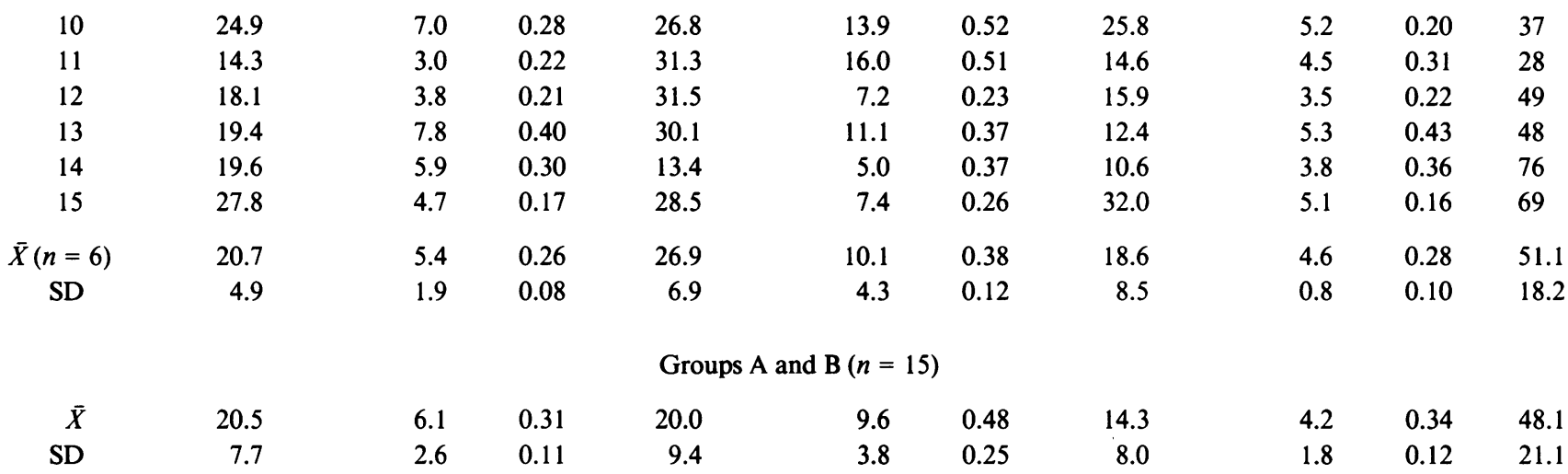

Group C: without reservoir function of the gallbladder

\begin{tabular}{|c|c|c|c|c|c|c|c|c|c|c|}
\hline 16 & 12.8 & 5.5 & 0.43 & 0 & & & 39.6 & 12.7 & 0.32 & \\
\hline 17 & 23.9 & 6.5 & 0.27 & 24.7 & 15.3 & 0.62 & 31.2 & 5.3 & 0.17 & 35 \\
\hline 18 & 13.3 & 5.6 & 0.42 & 0 & & & 21.0 & 9.6 & 0.46 & \\
\hline 19 & 8.9 & 3.5 & 0.39 & 11.2 & 8.6 & 0.77 & 17.0 & 8.8 & 0.52 & 103 \\
\hline 20 & 29.4 & 20.6 & 0.70 & 0 & & & 13.7 & 4.8 & 0.35 & \\
\hline 21 & 10.9 & 3.8 & 0.35 & 9.8 & 9.5 & 0.97 & 27.4 & 9.6 & 0.37 & 101 \\
\hline 22 & 10.1 & 6.6 & 0.66 & 0 & & & 21.4 & 11.8 & 0.55 & \\
\hline 23 & 26.1 & 7.0 & 0.27 & 15.1 & 8.2 & 0.55 & 16.9 & 8.6 & 0.51 & 105 \\
\hline $\bar{X}(n=8)$ & 16.9 & 7.4 & 0.44 & 7.6 & 10.4 & 0.73 & 23.5 & 8.9 & 0.40 & 86.0 \\
\hline SD & 8.2 & 5.5 & 0.16 & 9.2 & 3.3 & 0.19 & 8.7 & 2.8 & 0.13 & 34.0 \\
\hline \multicolumn{11}{|c|}{ Groups A, B, and C } \\
\hline $\bar{X}$ & 19.2 & 6.5 & 0.35 & 15.3 & 9.8 & 0.54 & 17.5 & 5.8 & 0.36 & 57.6 \\
\hline SD & 7.8 & 3.8 & 0.14 & 11.0 & 3.6 & 0.26 & 9.2 & 3.1 & 0.13 & 29.1 \\
\hline \multicolumn{11}{|c|}{ Control subjects } \\
\hline 1 & 37.6 & 5.6 & 0.15 & $44.5^{\ddagger}$ & ND & ND & 4.7 & 1.4 & 0.24 & ND \\
\hline 2 & 52.5 & 4.7 & 0.09 & 34.6 & 8.0 & 0.23 & 0.0 & 0.0 & 0.37 & 0 \\
\hline 3 & 26.5 & 14.6 & 0.55 & 20.7 & 24.2 & 1.17 & 24.9 & 8.5 & 0.34 & 35 \\
\hline 4 & 26.8 & 6.4 & 0.24 & 40.1 & 17.6 & 0.44 & 26.9 & 9.5 & 0.35 & 54 \\
\hline 5 & 29.2 & 5.5 & 0.19 & 16.4 & 4.6 & 0.28 & 13.9 & 3.0 & 0.22 & 65 \\
\hline
\end{tabular}


Table III. (Continued)

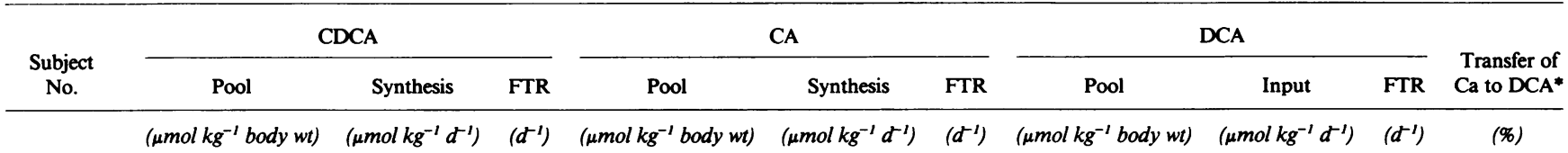

Control subjects (continued)

\begin{tabular}{crrrrrrrrrr}
6 & 20.9 & 3.3 & 0.16 & 15.2 & 5.4 & 0.36 & 9.2 & 2.1 & 0.23 & 39 \\
7 & 20.9 & 7.7 & 0.37 & 38.4 & 13.8 & 0.36 & 14.7 & 6.3 & 0.43 & 46 \\
8 & 35.6 & 5.0 & 0.14 & 38.7 & 7.0 & 0.18 & 19.3 & 4.4 & 0.23 & 63 \\
9 & 26.6 & 5.3 & 0.20 & 44.7 & 10.7 & 0.24 & 20.8 & 4.2 & 0.20 & 39 \\
10 & 16.0 & 4.8 & 0.30 & 0 & & & & 8.0 & 0.28 \\
11 & 20.1 & 6.2 & 0.31 & 25.4 & 8.1 & 0.32 & 14.7 & 3.7 & 0.25 & 46 \\
12 & 23.7 & 8.0 & 0.34 & 22.2 & 8.7 & 0.39 & 31.5 & 6.3 & 0.20 & 72 \\
13 & 16.8 & 3.0 & 0.18 & 20.3 & 5.9 & 0.09 & 10.8 & 1.1 & 0.10 & 19 \\
14 & 39.0 & 9.0 & 0.23 & 33.3 & 11.3 & 0.34 & 18.8 & 4.1 & 0.22 & 36 \\
15 & 13.2 & 2.6 & 0.20 & 18.0 & 6.7 & 0.37 & 4.0 & 0.7 & 0.17 & 10 \\
$X(n=15)$ & 27.0 & 6.1 & 0.24 & 27.5 & 10.2 & 0.37 & 16.2 & 4.2 & 0.26 & 40.3 \\
SD & 10.5 & 3.0 & 0.12 & 12.9 & 5.6 & 0.26 & 9.4 & 3.0 & 0.09 & 21.3 \\
& & & & & & & & & \\
\hline
\end{tabular}

* Transfer of CA to the DCA pool $=($ DCA input/CA synthesis $) \times 100$.

‡ This CA pool was calculated (24) from the kinetically determined CDCA pool size times the CA/CDCA molar ratio of intraoperative gallbladder bile.

transfer of CA to the DCA pool. This could be directly demonstrated by measurement of the ${ }^{13} \mathrm{C}$ label in the DCA pool (Fig. 3): after intake of $\left[{ }^{13} \mathrm{C}\right] \mathrm{CA}, 35-80 \%$ of the ${ }^{13} \mathrm{C}$ label peaked in the DCA pool within $24 \mathrm{~h}$. By contrast, controls (except subject 10 ) and gallstone patients of groups A and B (except subject 9 in group A) transferred less than half of that amount of ${ }^{13} \mathrm{C}$ label and reached peak enrichment of the DCA pool with ${ }^{13} \mathrm{C}$ 3-4 d after intake.

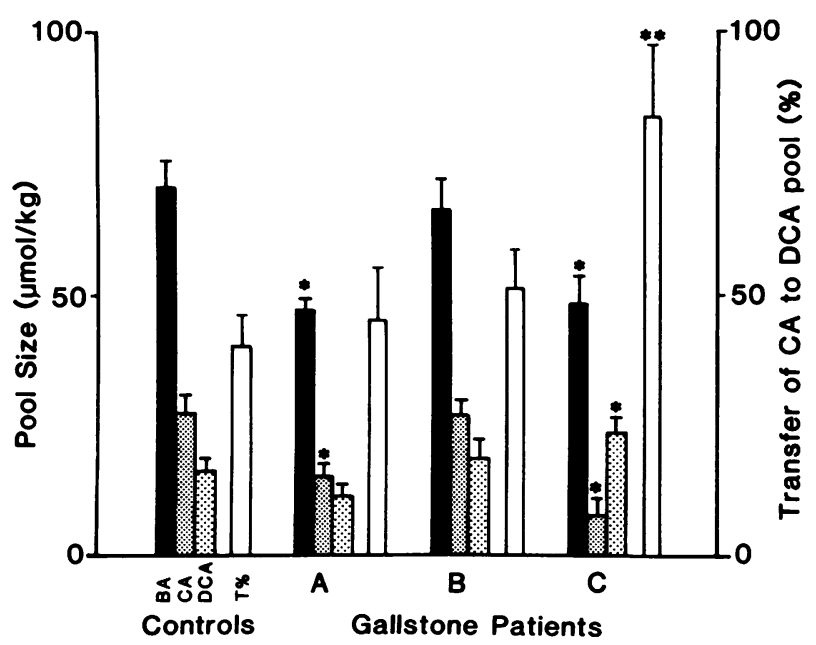

Figure 2. Patterns $(\overline{\mathrm{X}} \pm \mathrm{SEM})$ of bile acid pools and CA to DCA transfer in healthy controls $(n=15)$ and three groups of gallstone patients classified according to fraction of emptying of the gallbladder: $\mathrm{A}(n=9)$ with emptying gallbladder; $\mathrm{B}(n=6)$ with reduced emptying $(<50 \%)$ of the gallbladder; $\mathrm{C}(n=8)$ without gallbladder reservoir. Symbols and abbreviations: ( $\square$ ) bile acid (BA); (ם) CA pool; (ם) DCA pool; (ם) Percent transfer (T\%) of CA to the DCA pool (=DCA input/CA synthesis $\times 100$ ). *Significantly different from controls; ${ }^{* *}$ significantly different from all other groups.
Linear correlations with bile acid kinetics. The hepatic synthesis rates of CA and CDCA were directly correlated ( $r$ $=0.608, P<0.001)$. Input of DCA increased with the synthesis rate of its precursor CA $(r=0.511, P<0.01)$ and with the fractional transfer of CA to the DCA pool $(r=0.664, P$ $<0.001)$. The size of the CDCA pool was mainly related to CDCA synthesis rate $(r=0.559, P<0.005)$ and gallbladder fasting volume $(r=0.489, P<0.01)$. The size of the CA pool

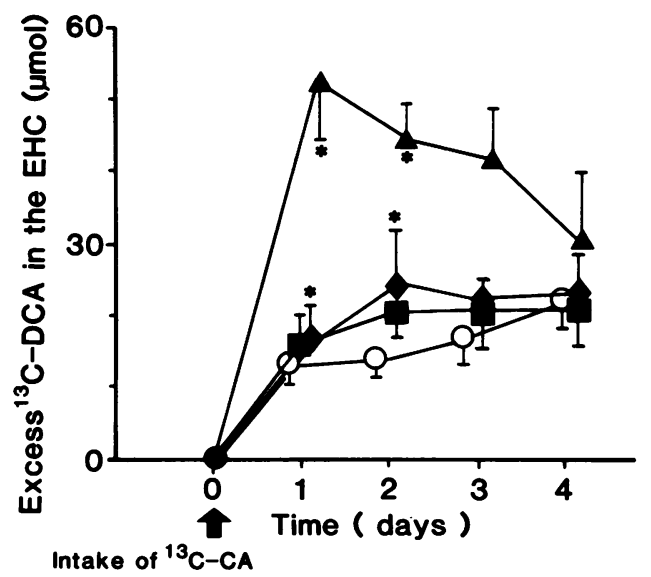

Figure 3. Time course of the amount of excess ${ }^{13} \mathrm{C}$-labeled DCA $(\overline{\mathrm{X}} \pm \mathrm{SEM})$ in the DCA pool after oral intake of $110 \mu \mathrm{mol}\left[{ }^{13} \mathrm{C}\right] \mathrm{CA}$ in controls $(0)(n=14)$, and three groups of gallstone patients: $(\bullet)$ group $\mathrm{A}(n=7) ;(\diamond)$ group $\mathrm{B}(n=6) ;(\triangle)$ group $\mathrm{C}(n=8)$ (compare Fig. 2). Note enhanced formation and increased input of $\left[{ }^{13} \mathrm{C}\right] \mathrm{DCA}$ in group $\mathrm{C}$ of gallstone patients. *Significantly different ( $\mathrm{C}$ vs. other groups). ${ }^{13} \mathrm{C}$ transfer was not determined in patients 1 and 2 in group $A$ and subject 1 in controls. 
Table IV. Lipid Composition of CCK-stimulated Duodenal Bile

\begin{tabular}{lccc}
\hline \multicolumn{1}{c}{ Group } & No. & Total lipids & $\begin{array}{l}\text { Cholesterol } \\
\text { saturation }\end{array}$ \\
\hline Gallstone patients & & $(\mathrm{g} / \mathrm{dl})$ & \\
Group A & 8 & $4.76 \pm 2.41$ & $1.27 \pm 0.07^{\S}$ \\
Group B & 6 & $5.23 \pm 3.03^{\prime \prime}$ & $1.40 \pm 0.23^{\S}$ \\
Group C & 7 & $2.78 \pm 1.24^{\S}$ & $1.53 \pm 0.35^{\S}$ \\
Controls & 15 & $5.26 \pm 1.73$ & $0.89 \pm 0.17$ \\
& & &
\end{tabular}

* In three subjects (10-12 in group B) intraoperative gallbladder bile was analyzed instead of CCK bile.

‡ Saturation index according to Carey’s Critical Tables (29).

${ }^{\S}$ Significantly different from controls $(P<0.02)$.

"Significantly different $(P<0.05$, group $C$ vs. B).

correlated poorly with CA synthesis rate $(r=+0.34 ; P=0.07)$ and inversely with the fractional transfer of CA to the DCA pool $(r=-0.38 ; P=0.03)$. The size of the DCA pool correlated $(r=0.80 ; P<0.001)$ with the input rate of DCA. Neither pool size nor input rate of DCA were related to age. The fraction of DCA in the total bile acid pool was correlated with the fraction of DCA $(r=0.71 ; P<0.001)$ and the cholesterol saturation index $(r=0.42 ; P=0.01)$ of CCK-stimulated bile, and with the total volume of the gallstones $(r=0.53 ; P<0.01)$.

Composition of biliary lipids (Table IV). CCK-stimulated duodenal bile was supersaturated (29) in all gallstone patients $(P<0.01$ vs. controls) and in 4 of 15 controls (subjects 4,10 , 12 , and 15), who either had a very small bile acid pool (subject 15 ) or a large DCA pool (subjects 4, 10, and 12). Gallstone patients showed an increased cholesterol/phospholipid ratio $(+41 \%,+58 \%,+54 \%$ in groups $\mathrm{A}, \mathrm{B}$, and $\mathrm{C} ; P<0.01$ vs. controls), but only group $C$ showed increased ratios of phospholipids/bile acids $(+41 \% ; P<0.02)$. The degree of cholesterol saturation was directly correlated with the fraction of DCA in biliary bile acids $(r=0.552 ; P=0.001)$ (Fig. 4$)$.

\section{Discussion}

This study substantiates the concept that the reduction of bile acid pool size in patients with cholesterol gallstones is caused by an increased turnover of the bile acid pools, not by a reduction of bile acid synthesis. The major new finding is a disorder of CA-DCA metabolism observed in a subgroup of gallstone patients, whose disease had progressed to loss of the reservoir function of the gallbladder.

Reduction of the bile acid pool is a common finding in non-obese cholesterol gallstone patients $(1,2,4-6)$, which has been explained by reduced synthesis of bile acids (12) or enhanced enterohepatic cycling of the bile acid pool $(3,5,9)$. Only in a group of Italian gallstone patients the reduction of the CA pool was caused by a combination of reduced synthesis and enhanced turnover (32). In our study and in studies of American whites $(1,3,4)$ and American Indians (33) gallstone patients had normal hepatic synthesis of bile acids. Also Swedish gallstone patients had bile acid synthesis not significantly decreased (5). Contrary to the hypothesis on feedback inhibition

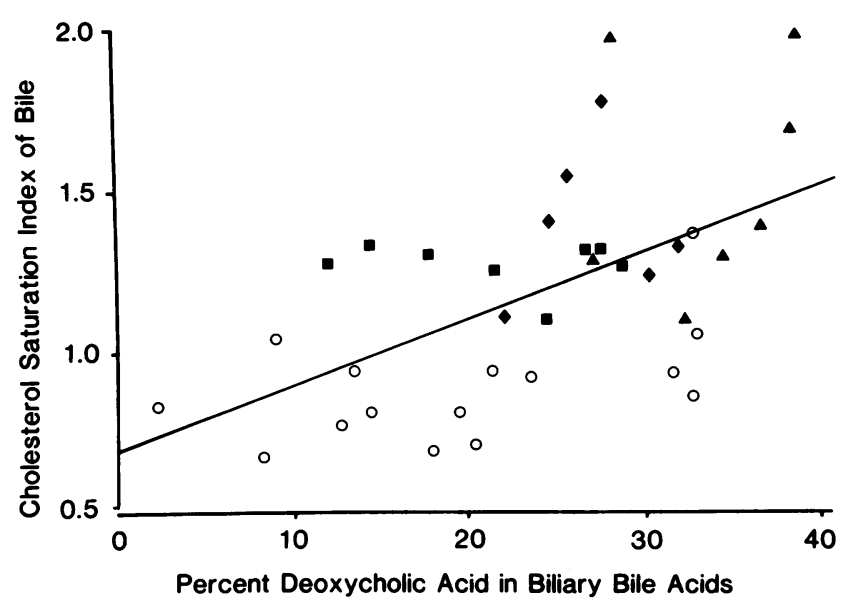

Figure 4. Cholesterol saturation (29) is correlated ( $r=0.552 ; P$ $=0.001$ ) with the percentage of DCA in bile acids of CCK-stimulated duodenal bile from healthy controls $(O)$ and from gallstone patients with normal emptying ( $\bullet$ (group $A, n=8$ ) or reduced emptying of the gallbladder $(\diamond)$ (group $\mathrm{B}, n=6$ ) and gallstone patients without reservoir function of the gallbladder ( $\triangle$ ) (group C, $n=7$ ).

of bile acid synthesis by DCA $(13,14)$, even the patients of group $\mathrm{C}$ with twofold increased input of DCA had normal bile acid synthesis. This strongly suggests that hepatic synthesis of bile acids is not deranged in gallstone disease. The reduction of the bile acid pool in gallstone disease is explained by increased fractional turnover of the bile acid pools $(1,2,4-6,33)$ (Table III, groups $\mathrm{A}$ and $\mathrm{C}$ ).

The increased turnover of the bile acid pools in gallstone patients, as observed in groups A and C (Table III), is thought to result from increased enterohepatic cycling of bile acids ( 3 , $9,12)$. This could be caused by enhanced emptying of the gallbladder, or by hastened transit (34) or decreased fractional absorption of bile acids in the small intestine. Emptying of the gallbladder is normal or reduced, but not enhanced, in gallstone patients $(35,36)$; reduced emptying of the gallbladder is associated with slower fractional turnover and larger pool size of bile acids in healthy subjects (34) as well as in gallstone patients (37) (Fig. 2, group B). Hastening the small intestinal transit enhances the turnover and reduces the size of the bile acid pool in healthy subjects to the extent seen in gallstone patients (34). We did not determine small intestinal transit time. However, mouth to cecum transit time had not been shortened in similar gallstone patients with functioning gallbladder (38). Alternatively, the increase $(+54 \%)$ in fractional turnover and the reduction $(-44 \%)$ of the CA pool in the gallstone patients of group A could be caused by a reduction in fractional absorption of CA by only 5\% (from $95.4 \%$ [3] to $90.5 \%$ ), provided the pool cycles at a normal rate of seven times per day (9). Such a small decrease in absorption of CA and CDCA cannot be excluded by the available studies $(3,12)$. Thus, the cause for the enhanced bile acid turnover is still unknown in gallstone disease.

Expansion of the DCA pool was related to increased input of DCA $(r=0.80 ; P<0.001)$. DCA was conserved in the enterohepatic circulation as efficiently as CDCA judged from similar fractional turnover rates. In this study, high input of DCA was not caused by old age or constipation, two factors 
reported to increase input of DCA $(17,39)$. Highly significant direct associations suggested that the input rate of DCA depended on the synthesis rate of its precursor $\mathrm{CA}$ and even more on the fractional transfer of CA to the DCA pool. This fractional transfer, which is usually less than $40 \%$ in healthy subjects (17), ranged up to $100 \%$.

Simultaneous turnover studies of CA and DCA revealed a disorder of CA-DCA metabolism in a subgroup of gallstone patients. This disorder can be described as an increased DCA input ( $>7 \mu \mathrm{mol} \mathrm{kg}{ }^{-1} \mathrm{~d}^{-1}$ ) or transfer $(>75 \%)$ of CA to DCA. It is associated with a reduced pool of $\mathrm{CA}$ and an expanded DCA pool (DCA/CA pool ratio > 1.5) (Fig. 2, group C). Between $35 \%$ and $80 \%$ of the ${ }^{13} \mathrm{C}$ label given as $\left[{ }^{13} \mathrm{C}\right] \mathrm{CA}$ by mouth appeared within $24 \mathrm{~h}$ as $\left[{ }^{13} \mathrm{C}\right] \mathrm{DCA}$ in the bile acid pool, whereas this transfer was $<25 \%$ in controls (Fig. 3 ). The accelerated and increased transfer of ${ }^{13} \mathrm{C}$ label implies faster degradation of CA to DCA as well as increased absorption of that DCA.

Which mechanism is responsible for the enhanced transfer of CA to DCA? In theory, two factors should be considered: accelerated loss of CA into the colon, where it is almost completely (>95\%) degraded to DCA (15), and increased bacterial conversion of CA to DCA in the small intestine. Both could be operative in patients without gallbladder reservoir (group $C$ ), because loss of the gallbladder reservoir ( $a$ ) enhances daily enterohepatic cycling (40) and loss of CA into the colon and (b) prolongs the time of daily exposure of CA to bacteria in the small intestine (41). Cholecystectomy, however, led only to a moderate increase (from $46 \%$ to $66 \%$ ) of the fraction of CA transferred to the DCA pool (21). On the other hand, the disorder occurred also in two of the women with normal gallbladder reservoir and emptying (subject 9 in group A and subject 10 in controls). Therefore, we speculate that other mechanisms in addition to loss of the gallbladder reservoir are involved. If ileal absorption of CA were impaired, rapid loss of $\mathrm{CA}$ into the colon would reduce the pool of $\mathrm{CA}$ and accelerate the conversion of CA to DCA and the input of that DCA. An alternative mechanism would be colonization of the distal small bowel with $7 \alpha$-dehydroxylating anaerobic bacteria. CA could then be more rapidly converted to DCA and that DCA could be well absorbed via the ileal bile acid transport system (42).

In patients with type III pattern of the bile acid pools the molar ratios of DCA/CA in fasting bile exceeded 1.0 (data not shown). Such high ratios have been reported for gallstone patients with nonvisualizing gallbladder in one (5) but not another study (43), for cholecystectomized gallstone patients in some $(41,44)$ but not other studies $(21,45)$, and for some conditions with a high risk of gallstone formation such as partial resection of the ileum (46) or hyperlipidemia type IIb or IV (47).

This study showed reasonable positive correlations between the fraction of DCA in the total bile acid pool and the DCA fraction $(r=0.65 ; P<0.005)$ and cholesterol saturation index ( $r=0.44 ; P<0.05$ ) of CCK-stimulated duodenal bile. The degree of cholesterol saturation of bile was also correlated with the fraction of DCA in biliary bile acids (Fig. 4). These associations support the concept that an expansion of the DCA fraction in the bile acid pool contributes to supersaturation of bile in gallstone disease.

Interestingly, the study revealed that bile was supersaturated in gallstone disease also in presence of a normal sized bile acid pool in subgroup B. In this group of patients, the reduced emptying of the gallbladder may have decreased the cycling of the pools and the secretion rate of bile acids. Low hepatic output of bile acids could increase cholesterol saturation by raising the secretory ratio of cholesterol to phospholipids (48).

Generally, loss of the gallbladder reservoir enhances enterohepatic cycling of bile acids (40) and lowers cholesterol saturation of bile $(4,21,43)$. Nevertheless, the patients in group $\mathrm{C}$ had supersaturated bile in spite of loss of the gallbladder reservoir, presumably because other factors had raised cholesterol content of bile. We speculate that supersaturation of bile in group $\mathrm{C}$ may have been caused by DCA-induced hypersecretion of cholesterol (10), in that these patients had a high fraction of DCA which exceeded the CA fraction in bile.

In summary, two different disturbances of bile acid metabolism, which are likely to contribute to supersaturation of bile with cholesterol, were observed in cholesterol disease: $(a)$ reduction of the bile acid pool and $(b)$ enhanced conversion of CA to DCA with replacement of the CA pool by an expanded DCA pool. The first disorder may be caused by more rapid loss of primary bile acids from the small intestine into the colon, the second disturbance may result from enhanced $7 \alpha$-dehydroxylation of CA (possibly in the ileum) and increased absorption of newly formed DCA.

\section{Acknowledgments}

We thank Ms. Dorothe Nissle for evaluation of the dietary records. The skillful technical assistance of Mrs. Elke Koenig, Mrs. Renate Artmann, Ms. Heide Krahl, and Ms. Brigitte Ruhland is gratefully acknowledged.

This work was supported by the Deutsche Forschungsgemeinschaft (grant Be 890/2-1,2).

\section{References}

1. Swell, L., C. C. Bell, and Z. R. Vlahcevic. 1971. Relationship of bile acid pool size to biliary lipid excretion and the formation of lithogenic bile in man. Gastroenterology. 61:716-722.

2. Pomare, E. W., and K. W. Heaton. 1973. Bile salt metabolism in patients with gallstones in functioning gallbladders. Gut. 14:885-890.

3. Northfiled, T. C., and A. F. Hofman. 1975. Biliary lipid output during three meals and an overnight fast. Gut. 16:1-17.

4. Shaffer, E. A., and D. M. Small. 1977. Biliary lipid secretion in cholesterol gallstone disease: the effects of cholecystectomy and obesity. J. Clin. Invest. 59:828-840.

5. Nilsell, K., B. Angelin, B. Leijd, and K. Einarsson. 1985. Biliary lipid output and bile acid kinetics in cholesterol gallstone disease. Gastroeneterology. 89:287-293.

6. Reuben, A., P. N. Maton, G. M. Murphy, and R. H. Dowling. 1985. Biliary lipid secretion in obese and non-obese individuals with and without gallstones. Clin. Sci. 69:71.

7. Marcus, S. N., and K. W. Heaton. 1988. Deoxycholic acid and the pathogenesis of gallstones. Gut. 29:522-533.

8. Holzbach, R. T. 1989. Pathogenesis and medical treatment of gallstones. In Gastrointestinal Disease. M. H. Sleisenger, and J. S. Fordtran, editors. W. B. Saunders Co., Philadelphia. 1668-1691.

9. Carey, M. C., and M. J. Cahalane. 1988. Enterohepatic circulation. In The Liver: Biology and Pathobiology. 2nd edition. I. M. Arias, W. B. Jakoby, H. Popper, D. Schachter, and D. A. Shafritz, editors. Raven Press, New York.

10. Caruli, N., P. Loria, M. Bertolotti, M. Ponz de Leon, D. Menozzi, G. Medici, and I. Piccagli. 1984. Effects of acute changes of bile acid pool composition on biliary lipid secretion. J. Clin. Invest. 74:614-624.

11. Nilsell, K. 1990. Bile acid pool size and gallbladder storage capacity in gallstone disease. Scand. J. Gastroenterol. 25:389-394.

12. Mok, H. Y. I., K. von Bergmann, and S. M. Grundy. 1977. Regulation of pool size of bile acids in man. Gastroenterology. 73:684-90.

13. Heuman, D. M., Z. R. Vlahcevic, M. L. Bailey, and P. B. Hylemon. 1988. Regulation of bile acid synthesis. II. Effect of bile acid feeding on enzymes regu- 
lating hepatic cholesterol and bile acid synthesis in the rat. Hepatology. 8:892897.

14. Stange, E. F., J. Scheibner, and H. Ditschuneit. 1989. Role of primary and secondary bile acids as feedback inhibitors of bile acid synthesis in the rat in vivo. J. Clin. Invest. 84:173-180.

15. Morris, J. S., T. S. Low-Beer, and K. W. Heaton. 1973. Bile salt metabolism and the colon. Scand. J. Gastroenterol. 8:425-431.

16. Hylemon, P. B. 1985. Metabolism of bile acids in intestinal microflora. In Sterols and Bile Acids. H. Danielson and J. Sjovall, editors. New Compr. Biochem. 12:331-343.

17. Van der Werf, S. D. J., A. W. M. Huijbregts, H. L. M. Lamers, G. P. Van Berge Henegouwen, and J. H. M. Van Tongeren. 1981. Age dependent differences in human bile acid metabolism and 7-dehydroxylation. Eur. J. Clin. Invest. $11: 425-431$.

18. Everson, G. T., D. Z. Braverman, M. L. Johnson, and F. Kern, Jr. 1980. A critical evaluation of real-time ultrasonography for the study of gallbladder volume and contraction. Gastroenterology. 79:40-46.

19. Pomeranz, I. S., and E. A. Shaffer. 1985. Abnormal gallbladder emptying in a subgroup of patients with gallstones. Gastroenterology. 88:787-791.

20. Hopman, W. P. M., P. J. S. Kerstens, J. B. M. Jansen, G. Rosenbusch, and C. B. H. Lamers. 1985. Effect of graded physiological doses of cholecystokinin on gallbladder contraction measured by ultrasonography. Gastroenterology. 89:1242-1247.

21. Berr, F., F. Stellaard, E. Pratschke, and G. Paumgartner. 1989. Effects of colecystectomy on the kinetics of the primary and secondary bile acids. J. Clin. Invest. 83:1541-1550.

22. Stellaard, F., M. F. Sackmann, F. Berr, and G. Paumgartner. 1987. Simultaneous determination of pool sizes and fractional turnover rates of deoxycholic acid in man by isotope dilution with ${ }^{2} \mathrm{H}$ and ${ }^{13} \mathrm{C}$ labels and serum sampling. Biochem. Environ. Mass Spectrom. 14:609-611.

23. White, E. C., D. J. McNamara, and E. H. Ahrens. 1981. Validation of a dietary record system for the estimation of daily cholesterol intake of individual outpatients. Am. J. Clin. Nutr. 34:199-203.

24. Hofmann, A. F., and N. E. Hoffman. 1974. Measurement of bile acid kinetics of isotope dilution in man. Gastroenterology. 67:314-323.

25. Abell, L. L., B. B. Levy, B. B. Brodie, and F. E. Kendall. 1952. A simplified method for the estimation of total cholesterol in serum and demonstration of its specificity. J. Biol. Chem. 195:357-59.

26. Bartlett, G. R. 1959. Phosphorus assay in column chromatography. J. Biol. Chem. 234:446-468.

27. Berr, F., F. Stellaard, A. Goetz, C. Hammer, and G. Paumgartner. 1988. Ethinylestradiol stimulates a biliary cholesterol-phospholipid cosecretion mechanism in the hamster. Hepatology. 8:619-624.

28. Kuroki, S., B. I. Cohen, M. C. Carey, and E. H. Mosbach. 1986. Rapid computation with the personal computer of the percent cholesterol saturation of the bile samples. J. Lipid Res. 27:442-446.

29. Carey, M. C. 1978. Critical tables for calculating the cholesterol saturation of native bile. J. Lipid Res. 19:945-955.
30. Winer, B. J. 1971. Statistical principles in experimental design. McGrawHill Book Co., New York. 42.

31. Snedecor, G. W., and W. G. Cochran, editors. 1980. Statistical Methods 7th editition. Iowa State University Press, Ames, IA. 149-188.

32. Roda, E., R. Aldini, G. Mazzella, A. Roda, C. Sama, D. Festi, and L. Barbara. 1978. Enterohepatic circulation of bile acids after cholecystectomy. Gut. 19:640-649.

33. Bell, C. C., Z. R. Vlahcevic, J. Prazich, and L. Swell. 1973. Evidence that a diminished bile acid pool precedes the formation of cholesterol gallstones in man Surg. Gynecol. Obstet. 289:1213-6.

34. Duane, W. C., and K. C. Hanson. 1978. Role of gallbladder emptying and small bowel transit in regulation of bile acid pool size in man. J. Lab. Clin. Med. 92:858-872.

35. Fisher, R. S., F. Stelzer, E. Rock, and L. S. Malmud. 1982. Altered gallbladder empyting in patients with gallstones. Dig. Dis. Sci. 27:1019-1024.

36. Festi, D., R. Frabboni, F. Bazzoli, A. Sangermano, M. Ronchi, L. Rossi, P. Parnini, M. Orsini, A. M. M. Primerano, G. Mazzella, et al. 1990. Gallbladder motility in cholesterol gallstone disease: effect of ursodeoxycholic acid administration and gallstone dissolution. Gastroenterology. 99:1779-1785.

37. Hepner, G. W. 1975. Effects of decreased gallbladder stimulation on enterohepatic cycling and kinetics of bile acids. Gastroenterology. 68:1574-1581.

38. Penagini, R., R. C. Spiller, J. J. Misiewicz, P. G. Frost, and D. B. A. Silk. 1988. Effect of cholecystectomy on mouth-to-cecum transit of a liquid meal. Dig. Dis. Sci. 33:19-22.

39. Marcus, S. N., and K. W. Heaton. 1986. Intestinal transit, deoxycholic acid and cholesterol saturation of bile-three interrelated factors. Gut. 27:550-558.

40. Malagelada, J. R., W. V. L. Go, W. J. Summerskill, and W. S. Gamble. 1973. Bile acid secretion and biliary bile acid composition altered by cholecystectomy. Dig. Dis. Sci. 18:455-45.

41. Hepner, G. W., A. F. Hofmann, J. R. Malagelada, P. A. Szcepanik, and P. D. Klein. 1974. Increased bacterial degradation of bile acids in cholecystectomized patients. Gastroenterology. 66:556-564.

42. Krag, E., and S. F. Phillips. 1974. Active and passive bile acid absorption in man. J. Clin. Invest. 53:1686-1694.

43. Redinger, R. N. 1976. The effect of loss of gallbladder function on biliary lipid composition in subjects with cholesterol gallstones. Gastroenterology. 71:470-474.

44. Pomare, E. W., and K. W. Heaton. 1973. The effect of cholecystectomy on bile salt metabolism. Gut. 14:753-762.

45. Van der Linden, W., B. Katzenstein, and F. Nakayama. 1983. The possible carcinogenic effect of cholecystectomy. Cancer. 52:1265-68.

46. Abaurre, R., S. G. Gordon, J. G. Mann, and F. Kern, Jr. 1969. Fasting bile salt pool size and composition after ileal resection. Gastroenterology. 57:679-88.

47. Ahlberg, J., B. Angelin, K. Einarsson, K. Hellstroem, and B. Leijd. 1980. Biliary lipid composition in normo- and hyperlipoproteinemia. Gastroenterology. 79:90-94.

48. Wagner, C. I., B. W. Trotman, and R. D. Soloway. 1976. Kineitc analysis of biliary lipid excretion in man and dog. J. Clin. Invest. 57:473-477. 